\title{
Management of Infectious Complications Associated with Acute-on-Chronic Liver Failure
}

\author{
Cornelius Engelmann Thomas Berg \\ Section Hepatology, Department of Gastroenterology and Rheumatology, University Hospital Leipzig, Leipzig, Germany
}

\section{Keywords}

Acute-on-chronic liver failure, ACLF · Infections .

Inflammation - Multi-resistant bacteria

\section{Summary}

Introduction: Acute-on-chronic liver failure (ACLF) is associated with a high susceptibility to infections leading to complications and poor prognosis. The sensitized immune system overwhelmingly responds to invading bacteria leading to organ damage. After resolution of infection or prolonged disease duration, the phagocytic system becomes irresponsive with a reduced bacterial clearance capacity promoting secondary infection. Methods: This review focuses on the best management strategies for patients with ACLF and infections. Using the following terms, an extensive literature research on the Medline database was performed: 'acute-on-chronic liver failure', 'infection', 'ACLF', 'bacteria', 'multi-resistance'. Results: Analysis of the literature confirmed that delayed diagnosis and treatment of infections in patients with ACLF results in a poor prognosis. Patients with ACLF should be considered as having a potential infection and should undergo a complete screening for sepsis. Once biochemical analysis indicates a potential infection, such as abnormal levels of C-reactive protein and procalcitonin, antibiotic treatment should be initiated immediately without microbiological culture results. For community-acquired infections third-generation cephalosporins are still the first choice, whereas in the nosocomial setting antibiotics with broader spectrum, such as piperacillin/combactam or carbapenems \pm glycopeptides, are preferred. The patient should be re-assessed $48 \mathrm{~h}$ after treatment initiation in order to tailor the treatment. Non-response is suspicious, likely due to bacterial resistance or fungal infection, which should be considered when choosing further treatment strategies. Albu- min substitution to prevent hepatorenal syndrome and to improve patients' outcome is mandatory in patients with spontaneous bacterial peritonitis. Prophylactic antibiotic therapy is suitable to prevent infections in highrisk patients. Conclusion: The screening for infections and its treatment is an essential part of managing patients with ACLF. In order to improve patients' prognosis, antibiotic treatment should be initiated once an infection is suspected. However, preventive strategies are already established and should be applied according to the guidelines.

(c) 2018 S. Karger GmbH, Freiburg

\section{Introduction}

Bacterial infections are the most common complications of acute-on-chronic liver failure (ACLF), accounting for about onefourth of all hospital admissions in patients with cirrhosis [1]. Up to $50 \%$ of patients with ACLF in general, and even more than $80 \%$ of critically ill patients with ACLF grade 3 develop infections during their hospital stay [1], which is significantly more than $20 \%$ in patients with simple acute decompensated liver cirrhosis $[1,2]$. The likelihood of infections is $4-5$ times higher than in the normal population [3], suggesting that chronic liver disease patients are more sensitive to infection.

Furthermore, there are 2 more indicators for this increased susceptibility to bacterial infections in patients with cirrhosis. First, infectious complications account for more than one-third of ACLF episodes, being the most frequent precipitating event reported in the CANONIC Study [4]; and second, this type of complication has a deleterious effect on patients' outcome. Infections in patients with cirrhosis can lead to more severe disease courses with a high rate of sepsis [5], increasing the infection-related risk of death by a factor of 3.75 compared to healthy liver patients with a general 30 -

\section{KARGER}

(๑) 2018 S. Karger GmbH, Freiburg
Prof. Dr. med. Thomas Berg Section Hepatology, Department of Gastroenterology and Rheumatology University Hospital Leipzig

Liebigstraße 20, 04103 Leipzig, Germany

thomas.berg@medizin.uni-leipzig.de 
day mortality rate of $38 \%$ [6]. In infection-triggered ACLF, the likelihood of death is 4 times higher than for all other precipitating events [7] and the ACLF-related death rate increases from onethird [4] to more than 70\% [7]. The risk for bacterial infections in cirrhosis increases with poor liver function, varicella bleeding, low ascites fluid protein level, prior spontaneous bacterial peritonitis (SBP), and hospitalization $[8,9]$.

This review considers the most recent literature regarding infections and cirrhosis to determine the best treatment strategies for patients with ACLF and infections.

\section{Epidemiology}

A large retrospective North American study using the NACSELD database identified urinary tract infections (UTI) and SBP as the most frequent sites of infection, causing about $50 \%$ of all documented episodes (UTI 28.5\%, SBP 22.5\%). Spontaneous bacteremia (13.2\%), skin/soft tissue infections (12.2\%), and respiratory infections were other common causes. Clostridium difficile colitis developed in only $4.1 \%$ of cases [10]. During a patient's hospital stay, there is a clear shift towards UTI (32\%) and respiratory infections (25\%), while the rate of SBP is reduced (12.5\%) once patients develop a second infection. This is potentially related to healthcare-related interventions such as urinary catheters [10].

Traditionally, bacterial infections in patients with cirrhosis are believed to be strongly associated with gram-negative pathogens [8, 9]. However, along with a rising number of healthcare-associated (56\%) or nosocomial infections (20\%), gram-positive bacteria have also been reported, being more frequent (36\%) than their gramnegative counterparts (30\%) [11]. In SBP, there are more reports of the gram-positive pathogens, Enterococci, with potentially high intrinsic resistance, particularly in the nosocomial setting [12]. The latter aspect shows an emerging problem of a bacterial spectrum shift in cirrhosis.

Most likely due to the frequent use of antibiotics within the last decades, multi-resistant (MR) bacteria are more frequently detected in chronic liver diseases $[13,14]$. Its spectrum ranges from 'simple' non-fermentable gram-negative bacilli (e.g. Pseudomonas aeroginosa, Stenotrophomonas maltophilia) to the well-known, extended-spectrum, beta-lactamase-producing Enterobacteriaceae (ESBL) and methicillin-resistant Staphylococcus aureus (MRSA), and finally to the relatively new strains of vancomycin-resistant Enterococci (VRE) [3]. Whereas community-acquired infections still have a low rate of MR bacteria (0-16\%), its frequency rises sharply up to $40 \%$ in healthcare-associated and nosocomial infections [13-15]. The prevalence of ESBL-producing Enterobacteriaceae, which is the predominant resistant bacteria detected in patients with cirrhosis in Europe [13, 15], varies from 2 to 30\% [3]. However, MR bacteria are often not considered for the initial empirical treatment of infection when culture results and resistance profiles are not yet available. As a consequence, multi-resistance leads to higher rates of septic shock (26 vs. $10 \%$ ) and mortality rates of $67 \%[1,13,16-18]$.
It is important to highlight that although bacteria are the main cause of infection in the context of cirrhosis, fungi can also cause severe complications. Although the overall rate of fungal infection is low, i.e. between $2-4 \%$, it causes a mortality rate of about $70 \%$. Frequent use of antibiotics and prolonged hospital stays may increase its frequency to nearly $10 \%[1,11,18-20]$.

\section{Pathomechanisms}

Endogenous bacterial translocation from the intestine is one of the most important mechanisms for SBP. This so-called intestinal bacterial translocation also occurs in healthy humans, by carefully balancing the local intestinal immune system to remove any intrinsic pathogen, which prevents bacteria circulating in the bloodstream. In cirrhosis, the homeostasis between translocation and bacterial clearance is significantly impaired, leading to a migration of predominantly gram-negative bacteria into the bloodstream and subsequent seeding into other body compartments, such as the peritoneal cavity. Several factors such as an increased leaky gut, impaired gut motility, and a quantitative and qualitative intestinal dysbiosis promote this bacterial translocation $[3,9,21]$. Moreover, the cirrhosis-associated immune dysfunction facilitates not only endogenously triggered infection but also the invasion of bacteria via other routes, e.g. causing pneumonia or UTI [22].

Interestingly, infections or bacteria in general seem to have a high capacity to induce organ damage leading to ACLF in cirrhosis $[3,4]$.

The constant translocation of bacteria and their products sensitizes the immune system so that invading pathogens cause an overwhelming inflammatory response [23, 24]. Circulating bacterial products are recognized by pattern-recognition receptors (PRR), which typically belong to the Toll-like receptor (TLR) and NODlike receptor families $[23,24]$, and its binding induces the transcriptional upregulation of a battery of proinflammatory genes specifically coding for cytokines such as interleukin-6 (IL6) and tumor necrosis factor alpha (TNFa). Thus, circulating levels of proinflammatory cytokines are higher in patients with cirrhosis than in healthy liver subjects $[25,26]$, and increase with the severity of liver disease [27], which is an indicator that the intensity of bacterial translocation correlates with the degree of liver dysfunction. The systemic inflammatory response induces organ damage by a reduced organ perfusion, endothelial dysfunction, and oxidative stress [3]. As a second mechanism, pathogens themselves or via endotoxins might promote a direct tissue-damaging effect. Hepatocytes are, under normal conditions, relatively protected against lipopolysaccharide(LPS)-induced tissue damage as the upregulation of nuclear factor(NF)- $\mathrm{kB}$ activates protective pathways. This mechanism is impaired in cirrhosis so that LPS binding to TLR4 leads to direct tissue damage [28, 29] (fig. 1).

A third mechanism does not contribute to organ damage itself but determines the clinical course of ACLF. Patients who survived either an ACLF-related infection or prolonged intensive care unit stay migrate into an immunosuppressive state $[24,30]$. Monocytes 


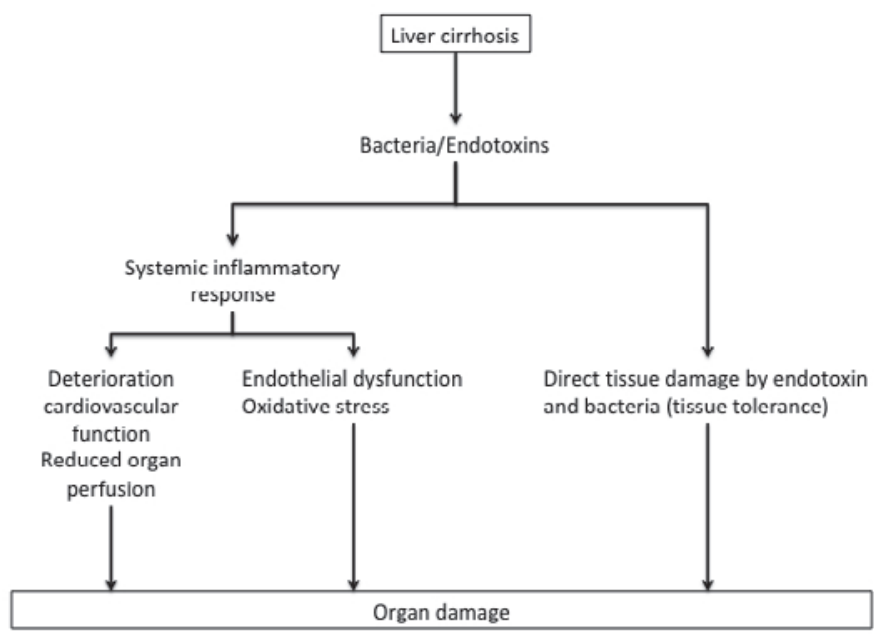

Fig. 1. Mechanisms involved in infection-related organ damage in patients with cirrhosis. Bacteria and their by-products can promote an indirect tissuedamaging effect by inducing a systemic inflammatory response with impaired cardiovascular function, thus triggering reduced organ perfusion as well as endothelial dysfunction and oxidative stress. Additionally, cytokines, and bacteria can mediate tissue damage directly.

and other phagocyting cells are less active with a reduced expression of human leukocyte antigen-antigen D related (HLA-DR), and as a consequence show an impaired response to LPS stimulation [31]. This hampers the clearance of invading bacteria, ultimately increasing the risk for secondary infectious complications [32]. This immunosuppressant state might also explain why patients have, in comparison to patients without infections, a persistently increased mortality after successful treatment $[6,33]$.

\section{Diagnostics}

The systemic inflammation is a typical feature in all patients with ACLF and is not restricted to patients with a potential infection, although the latter can induce higher levels of inflammatory markers [1]. The actual challenge is to distinguish between patients with a high likelihood of an ongoing infection from those who have a 'simple' sterile immune response. This is tremendously important in order to select the adequate antibiotic treatment, which will ultimately reduce mortality [34].

Clinical parameters such as the arterial blood pressure or respiratory rate have a poor discriminative capacity for both sepsis and ACLF, as there is a significant overlap and both are based on variants of the sepsis-related organ failure assessment (SOFA) score [35]. The short version of the sepsis criteria, the quick SOFA, includes any alteration of mental status, systolic blood pressure $\leq 100 \mathrm{~mm} \mathrm{Hg}$ or respiratory rate $\geq 22$ breaths/min, and might serve as a useful bedside test to quickly assess the likelihood of an infection. Piano et al. [36] described its predictive capacity regarding the in-hospital mortality in patients with cirrhosis, which was significantly better than the conventional systemic inflammatory response syndrome (SIRS) criteria (AUROC of 0.732 vs. 0.606).

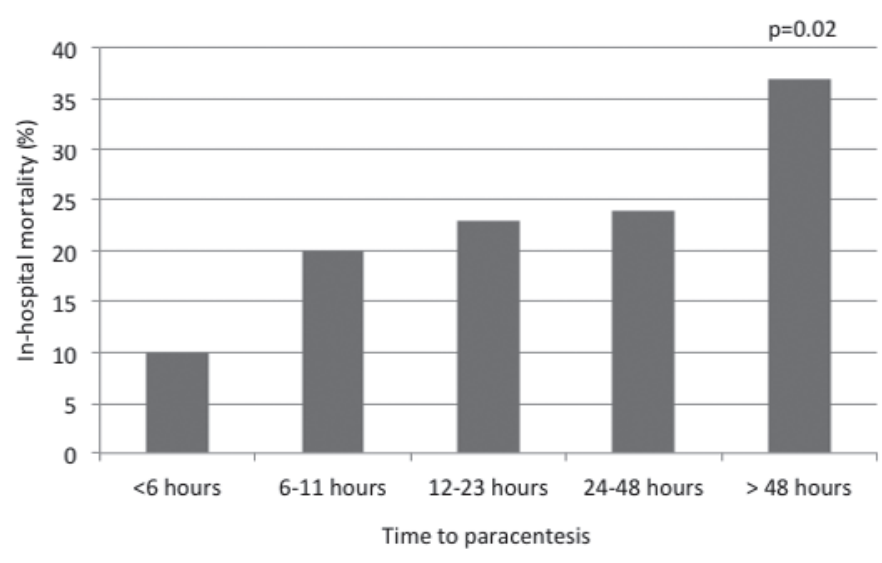

Fig. 2. The early diagnosis of infection is vital to allow for immediate treatment initiation and therefore improves patient prognosis. The survival probability of patients with spontaneous bacterial peritonitis is reduced by $3.3 \%$ for every hour a paracentesis is delayed [55].

However, its actual capacity to identify infections still needs to be evaluated. On the other hand, despite having an apparent infection, clinical signs are missing in a significant number of patients $(30-43 \%)[37,38]$. This implicates that the sensitivity and specificity of clinical markers are low, leaving patients and their physicians with uncertainty.

Conventional laboratory markers such as C-reactive protein (CRP) and procalcitonin (PCT) can improve the diagnostic management of patients with ACLF and a suspected infection. Although there is evidence that levels of both parameters are lower in patients with cirrhosis and infections compared to patients without liver disease [39], its accuracy in terms of predicting the presence of infection in cirrhosis is still high $[40,41]$. To summarize the existing literature, an individual cut-off for CRP of $24.7 \mathrm{ng} / \mathrm{ml}$ and PCT of $0.49 \mu \mathrm{g} / \mathrm{l}$ has a high predictive accuracy for the presence of a bacterial infection (CRP AUROC 0.811; PCT AUROC 0.89). Combining both parameters improves its sensitivity and subsequently its negative predictive value by about 10 to $>90 \%$ [40-43]. Other acute-phase proteins, such as IL6, might also serve as alternative biomarkers. IL6 does not only predict the outcome of patients with cirrhosis, comparable to the Model for End-stage Liver Disease (MELD) score and better than CRP levels and white blood cell count $[44,45]$, but it is also associated with the occurrence of infection [46]. LPS-binding protein levels and sCD14 have also been reported to correlate with infections but need further evaluation in a prospective cohort [47].

Criteria to diagnose SBP are well established and reliable; however, it requires a diagnostic paracentesis to collect liquid from ascites for an automatic or manual cell count. Once the number of ascites polymorphonuclear neutrophils (PMN) exceeds $250 / \mathrm{mm}^{3}$, the patient should be administered with immediate empirical antibiotic treatment, irrespective of microbiological culture results [48, 49]. After $48 \mathrm{~h}$ of antibiotic treatment, an effective response should see a reduction of more the $25 \%$ in ascites PMN count [48-50].

After the initial empiric phase of therapy, the antibiotic agents should be adjusted according to the detected pathogens from mi- 
Fig. 3. A guide for antibiotic treatment in patients with acute-on-chronic liver failure (ACLF) according to recommendations from Fernandez et al. [81]. A Empirical treatment of patients with ACLF according to the antibiotic stewardship program, which provides the best care to patients and to reduce the risk of selecting antibiotics for multidrug resistant bacteria. *Previous colonization, antibiotic treatment $\geq 5$ days in the last 3 months, hospitalization $\geq 5$ days in the last 3 months, nursing home/long-term care. ${ }^{* *}$ Pneumonia, secondary peritonitis (high bacterial load), high risk for severe complications (meningitis). ${ }^{* *} \geq 25 \mathrm{mg} / \mathrm{dl} .{ }^{*}$ Adding one or more of these antibiotics according to the local resistance, recent antibiotic treatment (within 6 weeks), and source of infection. ${ }^{\# \#} 2$ or more criteria: multifocal colonization with Candida spp., antibiotic treatment or steroids, parenteral nutrition, gastroduodenal surgery or pancreatitis, renal replacement therapy. B A guide for de-escalation according to the microbiological culture results and clinical course. ESBL = Extended-spectrum betalactamase; $\mathrm{MRCNS}=$ methicillin-resistant coagulase-negative Staphylococci; MRSA = methicillinresistant Staphylococcus aureus, VRE = vancomycin-resistant Enterococci, VSE = vancomycin-susceptible Enterococci.

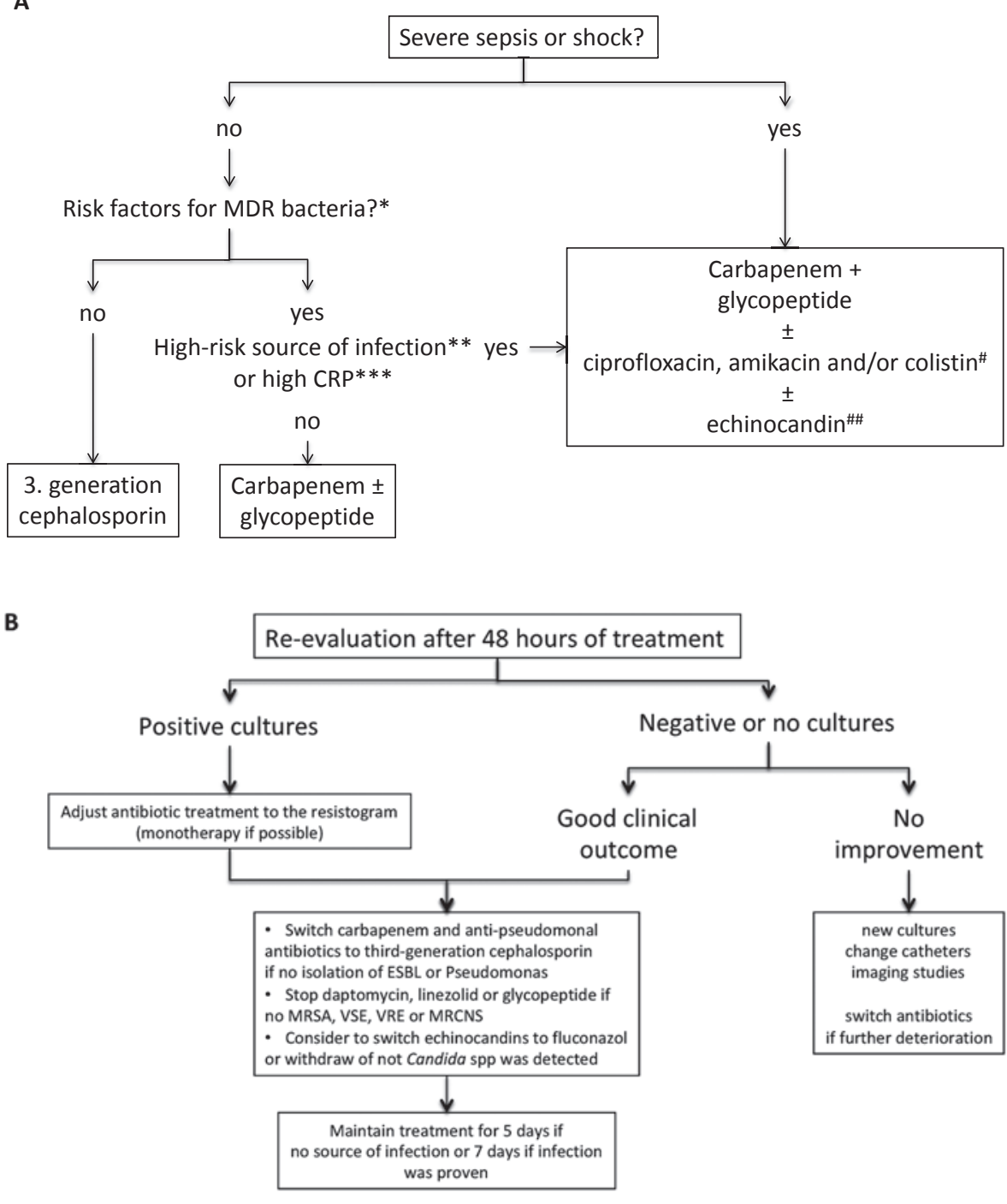

crobiological culture tests. This is most often not achievable as microbiological cultures remain negative in $30-50 \%$ of cirrhosis cases [11]. As to whether this is related to a high number of false-positive patients, identified as infectious by clinical and laboratory parameters, is certainly debatable, but it shows that conventional culture techniques are inappropriate to detect pathogens in patients with ACLF. There have been numerous attempts to improve the accuracy of pathogen detection, particularly by using molecular methods such as polymerase chain reaction (PCR), capturing predominantly the 16 s ribosomal gene which is specific for bacteria [51, 52]. The major points of criticisms are that due to a multitude of different PCR techniques results are difficult to compare. Using ultraclean reagents to avoid positive signals from contaminations can significantly boost its quality [53] and its significance as an additional diagnostic technique. This method quickly provides information about the presence or absence of pathogens and identifies pathogens down to species levels $[53,54]$.

\section{Treatment}

\section{Antibiotic Treatment}

Early detection of bacterial infections and prompt antibiotic therapy are essential in the management of patients with ACLF. Every hour without adequate treatment mortality rates increase by about 3.3\% [55] (fig. 2). In general, every patient with decompensated cirrhosis or ACLF should be considered positive for an infection and, therefore, requires a complete screening for infections. If predictors for infections, such as CRP and PCT, are positive, treatment should be initiated immediately. In order to avoid unnecessary therapy and potentially the selection of MR bacteria reassessment is mandatory after $48 \mathrm{~h}$ (fig. 3).

The choice of the initial treatment is tremendously important as it determines the patients' outcome. Once the antibiotic agent is inadequate, the likelihood of death rises to $74 \%[13,16]$. Therapeutic strategies in ACLF depend on the site, severity, and type (com- 
Table 1. Recommended antibiotic treatment according to Jalan et al. [3]

\begin{tabular}{|c|c|c|}
\hline Site of infection & Community-acquired & Nosocomial \\
\hline $\begin{array}{l}\text { SBP, } \mathrm{SBE} \text {, spontaneous } \\
\text { bacteremia }\end{array}$ & $\begin{array}{l}\text { cefotaxime or ceftriaxone or } \\
\text { amoxicillin/clavulanic acid }\end{array}$ & $\begin{array}{l}\text { piperacillin/tazobactam or } \\
\text { meropenem } \pm \text { glycopeptide }\end{array}$ \\
\hline Urinary tract infection & $\begin{array}{l}\text { uncomplicated: } \\
\text { ciprofloxacin or cotrimoxazole } \\
\text { sepsis: } \\
\text { cefotaxime or ceftriaxone or } \\
\text { amoxicillin/clavulanic acid }\end{array}$ & $\begin{array}{l}\text { uncomplicated: } \\
\text { Nitrofurantoin or fosfomycine } \\
\text { sepsis: } \\
\text { Piperacillin/tazobactam or } \\
\text { meropenem } \pm \text { glycopeptide }\end{array}$ \\
\hline Pneumonia & $\begin{array}{l}\text { amoxicillin/clavulanic acid or } \\
\text { ceftriaxone + macrolide or } \\
\text { levofloxacin or moxifloxacin }\end{array}$ & $\begin{array}{l}\text { piperacillin/tazobactam or } \\
\text { meropenem/ceftazidime + } \\
\text { ciprofloxacin } \\
\text { glycopeptides when high risk } \\
\text { for MRSA }\end{array}$ \\
\hline Cellulitis & $\begin{array}{l}\text { amoxicillin/clavulanic acid or } \\
\text { ceftriaxone + oxacillin }\end{array}$ & $\begin{array}{l}\text { meropenem/ceftazidime }+ \text { oxacillin } \\
\text { or glycopeptides }\end{array}$ \\
\hline
\end{tabular}

MRSA = Methicillin-resistant Staphylococcus aureus SBE = spontaneous bacterial empyema; $\mathrm{SBP}=$ spontaneous bacterial peritonitis. munity-acquired, healthcare-acquired, nosocomial) of bacterial infection. Whereas in community-acquired infection, third-generation cephalosporins remain the gold standard, it is recommended to select agents with a broader antibacterial spectrum, such as carbapenems [3], if the infection was acquired in hospitals (table 1). Data regarding a standardized therapy for nosocomial infections in patients with cirrhosis is sparse and difficult to implement, as the local resistance spectrum always needs to be considered. To date, there is only 1 prospective, randomized study for nosocomial SBP comparing ceftazidime with meropenem plus dapytomycin treatment. By choosing the latter treatment, response rates increased from 25 to $86.7 \%$ and responders had a $94 \%$ survival probability compared to $50 \%$ in non-responders [56]. Guidelines recommend piperacillin/combactam or meropenem plus glycopeptides in nosocomial infections [3]. The potential gram-positive pathogen spectrum in cellulitis and soft tissue infections explains the necessity to add oxacillin or glycopeptides, if not already prescribed [3] (table 1).

If patients are not responding to the empirically chosen antibiotic agent, bacterial resistance is likely, and the treatment must be tailored as soon as possible $[1,57]$. Fungal infections might also play a role once a nosocomial infection is not responding adequately [18-20], and antimycotic therapy should be considered accordingly (fig. 3). Moreover, in patients with SBP, secondary peritonitis must be suspected if the PMN count is high $\left(>1,000 / \mathrm{mm}^{3}\right)$. In this situation, a computer tomography scan to exclude an intestinal perforation or other causes should be considered [48].

\section{Preventions of Organ Failure}

Albumin improves hemodynamics and has strong immunomodulatory capacities [58]. In a randomized study in patients with SBP, substitution of $20 \%$ albumin reduced the incidence of renal failure and improved mortality rates from 29 to $10 \%$. However, this was only apparent in patients with bilirubin $>4 \mathrm{mg} / \mathrm{dl}$ and creatinine $>1 \mathrm{mg} / \mathrm{dl}[59,60]$. Albumin substitution is therefore mandatory in patients with SBP and ACLF $[48,49]$. A note of caution, albumin in infections other than SBP did not improve renal function or survival and even triggered pulmonary edemas in $8.3 \%$ of patients [61].

\section{Preventing Infections}

Prophylactic strategies are established for SBP and predominantly target the enteric gram-negative bacteria translocating from the intestine into the systemic circulation, which is the main pathomechanism for SBP. In this regard, norfloxacin, a poorly absorbable quinolone, is most often used to prevent infections in patients with cirrhosis $[48,49]$. However, given the potential of selecting multi-drug resistant pathogens under long-term use, this kind of treatment should be restricted to patients with a high risk of infection [50].

To date, there are 3 cohorts of patients who benefit from antibiotic prophylaxis treatment:

\section{Primary Prophylaxis SBP}

Patients with ascites and a low ascites protein concentration $(<15 \mathrm{~g} / \mathrm{l})$ in combination with high serum bilirubin $(>3 \mathrm{mg} / \mathrm{dl})$ or renal dysfunction (serum creatinine $>1.2 \mathrm{mg} / \mathrm{dl}$ ) or low platelet count $(<98$ exp9/l) have been identified to benefit from long-term norfloxacin treatment $400 \mathrm{mg}$ once daily $[62,63]$. This strategy reduced the rate of SBP from 61 to $7 \%$, of hepatorenal syndrome from 41 to $28 \%$, and improved 3-month survival from 62 to $94 \%$ [62]. Another study with ciprofloxacin showed an improved free- 
dom from bacterial infection of about $55-80 \%$ and enhanced 12 month survival from 66 to $86 \%$ [64], although the SBP rate was not altered. It is still unclear if patients with preserved liver function but low ascites protein content may benefit from prophylaxis [48]. Due to the significant side effects of long-term administration of antibiotics, the use of primary prophylaxis is most often restricted to patients awaiting liver transplantation in 3-6 months [3].

\section{Secondary Prophylaxis}

Relapse rates within 1 year after an SBP episode are about 70\% $[63,65]$. The frequency can be reduced to $20 \%$ by using a prophylaxis treatment [63]. Norfloxacin $400 \mathrm{mg}$ once daily is certainly the preferred treatment, although there are alternative strategies with ciprofloxacin $750 \mathrm{mg}$ once weekly or cotrimoxazole $960 \mathrm{mg}$ once daily; however, evidence is lacking [48]. Rifaximin, which is a nonabsorbable antibiotic frequently used for hepatic encephalopathy, is under current evaluation, notably because the risk for selecting multidrug-resistant bacteria is low and it is known to increase survival in cirrhosis with hepatic encephalopathy [66]. Although studies published so far suggest an improvement of the SBP rate, even in comparison to norfloxacin [67], current evidence still does not allow its broad use. However, data are restricted to patients with hepatitis $\mathrm{C}$ and populations from a single country [68-70]. Uncertainty remains regarding its true beneficial effect; notably as other prospective cohort studies could not confirm the positive results [71].

\section{Gastrointestinal Bleeding}

Patients with cirrhosis and gastrointestinal bleeding have a high risk of bacterial infections (25-65\%) [72-74], which in turn is associated with a high failure rate to control the bleeding and elevated mortality $[73,75]$. Antibiotic prophylaxis reduces the risk of bacterial infections by $10-20 \%$ and, moreover, decreases the likelihood for re-bleedings [76, 77]. Although oral quinolones seem to be effective in patients with preserved liver function [48], ceftriaxone (1-3 g/day for 7 days) or an equivalent third-generation cephalosporin is the preferred treatment in severely ill patients with ACLF, notably because the rate of quinolone-resistant pathogens has risen sharply within recent years $[48,62,78]$.

\section{Infections and Liver Transplantation}

There is increasing evidence that patients with ACLF, particularly with multi-organ failure and ACLF grade 3, have a good outcome after liver transplantation with a 1-year survival rate of $83.9 \%$ [79]. However, it is important to implement a strategy for managing the high risk of infectious complications. The study above showed that 56 out of 73 patients with ACLF grade 3 were trans- planted after being admitted with or developed infections during their hospital stay. Although those patients had a higher rate of complications after transplantation, notably infections, the equality in survival rates certainly proved the general applicability of the transplantation approach and suggests liver transplantation as a life-saving strategy. Although it is unclear as to whether a pre-emptive antibiotic treatment before and after liver transplantation effectively reduces infection rates or improves survival in this cohort, the deleterious consequences of infections strongly suggest that a strict follow-up in every patient is performed. An AISF consensus conference recommended in 2014 to closely monitor every patient for infectious complications and to treat appropriately if any signs of infection develop. Active infections most often require a temporary suspension from the waitlist [80], which puts the patients at risk of death without being transplanted.

\section{Conclusion}

This review summarized the most recent literature on infections and cirrhosis in order to develop an appropriate strategy on how to handle infections in patients with ACLF.

Bacterial infections are common in ACLF, either as its precipitating event or by complicating its course. Infection often results in a significant organ (tissue) damage and worsens a patient's prognosis. Early diagnosis and adequate treatment is essential, as it improves the patients' outcome. For the initial empirical choice of antibiotic agent, the site of infection, type, and the local resistance spectrum need to be considered. Positive predictors for bacterial infection in patients with ACLF should prompt a prophylactic strategy.

\section{Acknowledgement}

We would like to thank Laura A. Kehoe (Medical Communications) for her excellent proofreading.

\section{Disclosure Statement}

Cornelius Engelmann is funded by the German Research Foundation (DFG) (EN 1100/2-1). He has an ongoing research collaboration with Sequana Medical, Merz Pharmaceuticals, and Novartis. He received speaker fees from Novartis, Gilead, and Merz Pharmaceuticals.

Thomas Berg received: Research support from Abbvie, Roche, BMS, Gilead, Novartis, Merck/MSD, Intercept, Janssen, Novartis, Sequana Medical, and Pfizer; provided consultancy, speakers bureau and participated in advisory boards for Abbvie, Alexion, Bayer, Boehringer Ingelheim, BMS, Gilead, GSK, Intercept, Janssen, MSD/Merck, Merz, Novartis, Sequana Medical, and Roche. 


\section{References}

1 Fernandez J, Acevedo J, Wiest R, et al: Bacterial and fungal infections in acute-on-chronic liver failure: prevalence, characteristics and impact on prognosis. Gut 2017;DOI: 10.1136/gutjnl-2017-314240.

2 Katoonizadeh A, Laleman W, Verslype C, Wilmer A, Maleux G, Roskams T, Nevens F: Early features of acute-on-chronic alcoholic liver failure: a prospective cohort study. Gut 2010;59:1561-1569.

3 Jalan R, Fernandez J, Wiest R, et al: Bacterial infections in cirrhosis: a position statement based on the EASL Special Conference 2013. J Hepatol 2014;60:13101324.

4 Moreau R, Jalan R, Gines P, et al: Acute-on-chronic liver failure is a distinct syndrome that develops in patients with acute decompensated cirrhosis. Gastroenterology 2013;144:1426-1437.

5 Foreman MG, Mannino DM, Moss M: Cirrhosis as a risk factor for sepsis and death: analysis of the National Hospital Discharge Survey. Chest 2003;124:10161020.

6 Arvaniti V, D’Amico G, Fede G, Manousou P, Tsochatzis E, Pleguezuelo M, Burroughs AK: Infections in patients with cirrhosis increase mortality four-fold and should be used in determining prognosis. Gastroenterology 2010;139:1246-1256.

7 Mücke MM, Rumyantseva T, Mücke VT, Schwarzkopf K, Joshi S, Kempf VAJ, Welsch C, Zeuzem S, Lange $\mathrm{CM}$ : Bacterial infection-triggered acute-on-chronic liver failure is associated with increased mortality. Liver Int 2018;38:645-653.

8 Fernandez J, Gustot T: Management of bacterial infections in cirrhosis. J Hepatol 2012;56(suppl1):S1-12.

9 Gustot T, Durand F, Lebrec D, Vincent JL, Moreau R: Severe sepsis in cirrhosis. Hepatology 2009;50:20222033.

10 Bajaj JS, O’Leary JG, Reddy KR, et al.; North American Consortium For The Study Of End-Stage Liver Disease (NACSELD): Survival in infection-related acute-onchronic liver failure is defined by extrahepatic organ failures. Hepatology 2014;60:250-256.

11 Bajaj JS, O'Leary JG, Wong J, Reddy KR, Kamath PS: Bacterial infections in end-stage liver disease: current challenges and future directions. Gut 2012;61:12191225.

12 Shi L, Wu D, Wei L, et al: Nosocomial and community-acquired spontaneous bacterial peritonitis in patients with liver cirrhosis in China: comparative microbiology and therapeutic implications. Sci Rep 2017;7: 46025.

13 Fernandez J, Acevedo J, Castro M, et al: Prevalence and risk factors of infections by multiresistant bacteria in cirrhosis: a prospective study. Hepatology 2012;55: 1551-1561.

14 Woodford N, Turton JF, Livermore DM: Multiresistant gram-negative bacteria: the role of high-risk clones in the dissemination of antibiotic resistance. FEMS Microbiol Rev 2011;35:736-755.

15 Merli M, Lucidi C, Giannelli V, Giusto M, Riggio O, Falcone M, Ridola L, Attili AF, Venditti M: Cirrhotic patients are at risk for health care-associated bacterial infections. Clin Gastroenterol Hepatol 2010;8:979-985.

16 Cheong HS, Kang CI, Lee JA, Moon SY, Joung MK, Chung DR, Koh KC, Lee NY, Song JH, Peck KR: Clinical significance and outcome of nosocomial acquisition of spontaneous bacterial peritonitis in patients with liver cirrhosis. Clin Infect Dis 2009;48:1230-1236.

17 Campilo B; Richardet JP, Kheo T, Dupeyron C: Nosocomial spontaneous bacterial peritonitis and bacteremia in cirrhotic patients: impact of isolate type on prognosis and characteristics of infection. Clin Infect Dis 2002;35:1-10.
8 Bert F, Andreu M, Durand F, Degos F, Galdbart JO, Moreau R, Branger C, Lambert-Zechovsky N, Valla D: Nosocomial and community-acquired spontaneous bacterial peritonitis: comparative microbiology and therapeutic implications. Eur J Clin Microbiol Infect Dis 2003;22:10-15.

19 Piroth L, Pechinot A, Di Martino V, et al: Evolving epidemiology and antimicrobial resistance in spontaneous bacterial peritonitis: a two-year observational study. BMC Infect Dis 2014;14:287.

20 Friedrich K, Nüssle S, Rehlen T, Stremmel W, Mischnik A, Eisenbach C: Microbiology and resistance in first episodes of spontaneous bacterial peritonitis: implications for management and prognosis. J Gastroenterol Hepatol 2016;31:1191-1195.

21 Wiest R, Lawson M, Geuking M: Pathological bacterial translocation in liver cirrhosis. J Hepatol 2014;60:197209.

22 Albillos A, Lario M, Alvarez-Mon M: Cirrhosis-associated immune dysfunction: distinctive features and clinical relevance. J Hepatol 2014;61:1385-1396.

23 Arroyo V, Moreau R, Jalan R, Ginès P; EASL-CLIF Consortium CANONIC Study: Acute-on-chronic liver failure: a new syndrome that will re-classify cirrhosis. J Hepatol 2015;62(suppl1):S131-143.

24 Moreau R: Role of infections in acute-on-chronic liver failure. Dig Dis 2015;33:577-581.

25 Byl B, Roucloux I, Crusiaux A, Dupont E, Devière J: Tumor necrosis factor alpha and interleukin 6 plasma levels in infected cirrhotic patients. Gastroenterology 1993;104:1492-1497.

26 Deviere J, Content J, Denys C, Vandenbussche P, Schandene L, Wybran J, Dupont E: Excessive in vitro bacterial lipopolysaccharide-induced production of monokines in cirrhosis. Hepatology 1990;11:628-634.

27 Claria J, Stauber RE, Coenraad MJ, et al; CANONIC Study Investigators of the EASL-CLIF Consortium and the European Foundation for the Study of Chronic Liver Failure (EF-CLIF): Systemic inflammation in decompensated cirrhosis: characterization and role in acute-on-chronic liver failure. Hepatology 2016;64: 1249-1264.

28 Medzhitov R, Schneider DS, Soares MP: Disease tolerance as a defence strategy. Science 2012;335:936-941.

29 Tazi KA, Bieche I, Paradis V, et al: In vivo altered unfolded protein response and apoptosis in livers from lipopolysaccharide-challenged cirrhotic rats. J Hepatol 2007;46:1075-1088.

30 Hotchkiss RS, Monneret G, Payen D: Sepsis-induced immunosuppression: from cellular dysfunction to immunotherapy. Nat Rev Immunol 2013;13:862-874.

-31 Bernsmeier C, Triantafyllou E, Brenig R, et al: CD14+CD15-HLA-DR- myeloid-derived suppressor cells impair antimicrobial responses in patients with acute-on-chronic liver failure. Gut 2018;67:1155-1167.

32 Wasmuth HE, Kunz D, Yagmur E, TimmerStranghöner A, Vidacek D, Siewert E, Bach J, Geier A, Purucker EA, Gressner AM, Matern S, Lammert F: Patients with acute on chronic liver failure display 'sepsis-like’ immune paralysis. J Hepatol 2005;42:195-201.

33 Bajaj JS, O'Leary JG, Reddy KR, Wong F, Olson JC, Subramanian RM, Brown G, Noble NA, Thacker LR, Kamath PS; NACSELD: Second infections independently increase mortality in hospitalized patients with cirrhosis: the North American consortium for the study of end-stage liver disease (NACSELD) experience. Hepatology 2012;56:2328-2335.
Arabi YM, Dara SI, Memish Z, et al: Antimicrobial therapeutic determinants of outcomes from septic shock among patients with cirrhosis. Hepatology 2012; 56:2305-2315.

35 Singer M, Deutschman CS, Seymour CW, et al: The third international consensus definitions for sepsis and septic shock (sepsis-3). JAMA 2016;315:801-810.

36 Piano S, Bartoletti M, Tonon M, et al: Assessment of sepsis-3 criteria and quick SOFA in patients with cirrhosis and bacterial infections. Gut 2017;DOI: 10.1136/ gutjnl-2017-314324.

37 Le Moine O, Marchant A, De Groote D, Azar C, Goldman $\mathrm{M}$, Devière J: Role of defective monocyte interleukine-10 release in tumor necrosis factor-alpha overproduction in alcoholics cirrhosis. Hepatology 1995; 22:1436-1439.

38 Kim BI, Kim HJ, Park JH, Park D II, Cho YK, Sohn C II, Jeon WK, Kim HS, Kim DJ: Increased intestinal permeability as a predictor of bacterial infections in patients with decompensated liver cirrhosis and haemorrhage. J Gastroenterol Hepatol 2011;26:550-557.

39 Park WB, Lee KD, Lee CS, Jang HC, Kim HB, Lee HS, Oh MD, Choe KW: Production of C-reactive protein in Escherichia coli-infected patients with liver dysfunction due to liver cirrhosis. Diagn Microbiol Infect Dis 2005;51:227-230.

40 Tsiakalos A, Karatzaferis A, Ziakas P, Hatzis G: Acutephase proteins as indicators of bacterial infection in patients with cirrhosis. Liver Int 2009;29:1538-1542.

41 Papp M, Vitalis Z, Altorjay I, Tornai I, Udvardy M, Harsfalvi J, Vida A, Kappelmayer J, Lakatos PL, AntalSzalmas P: Acute phase proteins in the diagnosis and prediction of cirrhosis associated bacterial infections. Liver Int 2012;32:603-611.

42 Li CH, Yang RB, Pang JH, Chang SS, Lin CC, Chen $\mathrm{CH}$, Chen HY, Chiu TF: Procalcitonin as a biomarker for bacterial infections in patients with liver cirrhosis in the emergency department. Acad Emerg Med 2011; 18:121-126.

43 Schuetz P, Albrich W, Mueller B: Procalcitonin for diagnosis of infection and guide to antibiotic decisions: past, present and future. BMC Med 2011;9:107.

44 Remmler J, Schneider C, Treuner-Kaueroff T, Bartels M, Seehofer D, Scholz M, Berg T, Kaiser T: Increased level of interleukin-6 associates with increased 90-day and 1 -year mortality in patients with end-stage liver disease. Clin Gastroenterol Hepatol 2018;16:730-737.

45 Fischer J, Silva TE, Soares E, et al: From stable disease to acute-on-chronic liver failure: circulating cytokines are related to prognosis in different stages of cirrhosis. Cytokine 2017;91:162-169.

46 Wu Y, Wang M, Zhu Y, Lin S: Serum interleukin-6 in the diagnosis of bacterial infection cirrhotic patients: a meta-analysis. Medicine (Baltimore) 2016;95:e5127.

47 Albillos A, de-la-Hera A, Alvarez-Mon M: Serum lipopolysaccharide-binding protein prediction of severe bacterial infection in cirrhotic patients with ascites. Lancet 2004;363:1608-1610.

48 European Association for the Study of the Liver: EASL clinical practice guidelines on the management of ascites, spontaneous bacterial peritonitis, and hepatorenal syndrome in cirrhosis. J Hepatol 2010;53:397-417.

49 Runyon BA: Management of adult patients with ascites due to cirrhosis: an update. Hepatology 2009;49:20872107

50 Rimola A, Garcia-Tsao G, Navasa M, Piddock LJ, Planas R, Bernard B, Inadomi JM: Diagnosis, treatment and prophylaxis of spontaneous bacterial peritonitis: a consensus document. International Ascites Club. J Hepatol 2000;32:142-153. 
51 Zapater P, Frances R, Gonzalez-Navajas JM, et al: Serum and ascitic fluid bacterial DNA: a new independent prognostic factor in noninfected patients with cirrhosis. Hepatology 2008;48:1924-1931.

52 Serste T, Bert F, Leflon-Guibout V, et al: Detection of bacterial DNA in serum and ascitic fluid of asymptomatic outpatients with cirrhosis and non-neutrocytic ascites. Liver Int 2011;31:494-498.

53 Engelmann C, Krohn S, Prywerek D, Hartmann J, Herber A, Boehlig A, Zeller K, Boehm S, Berg T: Detection of molecular bacterascites in decompensated cirrhosis defines a risk with decreased survival. Eur J Gastroenterol Hepatol 2016;28:1285-1292.

54 Krohn S, Böhm S, Engelmann C, Hartmann J, Brodzinski A, Chatzinotas A, Zeller K, Prywerek D, Fetzer I, Berg T: Application of qualitative and quantitative real-time PCR, direct sequencing, and terminal restriction fragment length polymorphism analysis for detection and identification of polymicrobial 16S rRNA genes in ascites. J Clin Microbiol 2014;52:1754-1757.

55 Kim JJ, Tsukamoto MM, Mathur AK, Ghomri YM, Hou LA, Sheibani S, Runyon BA: Delayed paracentesis is associated with increased in-hospital mortality in patients with spontaneous bacterial peritonitis. Am J Gastroenterol 2014;109:1436-1442.

56 Piano S, Fasolato S, Salinas F, et al: The empirical antibiotic treatment of nosocomial spontaneous bacterial peritonitis: results of a randomized, controlled clinical trial. Hepatology 2016;63:1299-309.

57 Lutz P, Nischalke HD, Krämer B, et al: Antibiotic resistance in healthcare-related and nosocomial spontaneous bacterial peritonitis. Eur J Clin Invest 2017;47: 44-52.

58 Garcia-Martinez R, Caraceni P, Bernardi M, Gines P, Arroyo V, Jalan R: Albumin: pathophysiologic basis of its role in the treatment of cirrhosis and its complications. Hepatology 2013;58:1836-1846.

59 Sort P, Navasa M, Arroyo V, Aldeguer X, Planas R, Ruiz-del-Arbol L, Castells L, Vargas V, Soriano G, Guevara M, Ginès P, Rodés J: Effect of intravenous albumin on renal impairment and mortality in patients with cirrhosis and spontaneous bacterial peritonitis. N Engl J Med 1999;341:403-409.

60 Salerno F, Navickis RJ, Wilkes MM: Albumin infusion improves outcome of patients with spontaneous bacterial peritonitis: a meta-analysis of randomized trials. Clin Gastroenterol Hepatol 2013;11:123-130.

61 Thevenot T, Bureau C, Oberti F, et al: Effect of albumin in cirrhotic patients with infections other than spontaneous bacterial peritonitis. A randomized trial. J Hepatol 2015;62:822-830.
62 Fernandez J, Navasa M, Planas R, Montoliu S, Monfort D, Soriano G, Vila C, Pardo A, Quintero E, Vargas V, Such J, Ginès P, Arroyo V: Primary prophylaxis of spontaneous bacterial peritonitis delays hepatorenal syndrome and improves survival in cirrhosis. Gastroenterology 2007;133:818-824.

63 Gines P, Rimola A, Planas R, et al: Norfloxacin prevents spontaneous bacterial peritonitis recurrence in cirrhosis: results of a double-blind, placebo-controlled trial. Hepatology 1990;12:716-724.

64 Terg R, Fassio E, Guevara M, Cartier M, Longo C, Lucero R, Landeira C, Romero G, Dominguez N, Muñoz A, Levi D, Miguez C, Abecasis R: Ciprofloxacin in primary prophylaxis of spontaneous bacterial peritonitis: a randomized, placebo-controlled study. J Hepatol 2008;48:774-779.

65 Garcia-Tsao G: Current management of the complications of cirrhosis and portal hypertension: variceal haemorrhage, ascites, and spontaneous bacterial peritonitis. Gastroenterology 2001;120:726-748.

66 Kang SH, Lee YB, Lee JH, et al: Rifaximin treatment is associated with reduced risk of cirrhotic complications and prolonged overall survival in patients experiencing hepatic encephalopathy. Aliment Pharmacol Ther 2017; 46:845-855.

67 Elfert A, Abo Ali L, Soliman S, Ibrahim S, Abd-Elsalam S: Randomized-controlled trial of rifaximin versus norfloxacin for secondary prophylaxis of spontaneous bacterial peritonitis. Eur J Gastroenterol Hepatol 2016; 28:1450-1454.

68 Mostafa T, Badra G, Abdallah M: The efficacy and the immunmodulatory effect of rifaximin in prophylaxis of spontaneous bacterial peritonitis in cirrhotic Egyptian patients. Turk J Gastroenterol 2015;26:163-169.

69 Assem M, Elsabaawy M, Abdelrashed M, Elemam S, Khodeer S, Hamed W, Abdelaziz A, El-Azab G: Efficacy and safety of alternating norfloxacin and rifaximin as primary prophylaxis for spontaneous bacterial peritonitis in cirrhotic ascites: a prospective randomized open-label comparative multicentre study. Hepatol Int 2016;10:377-385.

70 Goel A, Rahim U, Nguyen LH, Stave C, Nguyen MH: Systematic review with meta-analysis: rifaximin for the prophylaxis of spontaneous bacterial peritonitis. Aliment Pharmacol Ther 2017;46:1029-1036.
1 Lutz P, Parcina M, Bekeredjian-Ding I, Nischalke HD Nattermann J, Sauerbruch T, Hoerauf A, Strassburg $\mathrm{CP}$, Spengler $\mathrm{U}$ : Impact of rifaximin on the frequency and characteristics of spontaneous bacterial peritonitis in patients with liver cirrhosis and ascites. Plos One 2014;9:e93909.

72 Hou MC, Lin HC, Liu TT, Kuo BI, Lee FY, Chang FY, Lee SD: Antibiotic prophylaxis after endoscopic therapy prevents rebleeding in acute variceal haemorrhage: a randomized trial. Hepatology 2004;39:746-753.

73 Bernard B, Grange JD, Khac EN, Amiot X, Opolon P, Poynard T: Antibiotic prophylaxis for the prevention of bacterial infections in cirrhotic patients with gastrointestinal bleeding: a meta-analysis. Hepatology 1999. 29:1655-1661.

74 Deschenes M, Villeneuve JP: Risk factors for the development of bacterial infections in hospitalized patients with cirrhosis. Am J Gastroenterol 1999;94:2193-2197.

75 Vivas S, Rodriguez M, Palacio MA, Linares A, Alonso JL, Rodrigo L: Presence of bacterial infection in bleeding cirrhotic patients is independent associated with early mortality and failure to control bleeding. Dig Dis Sci 2001;46:2752-2757.

76 Fernandez J, Ruiz del Arbol L, Gomez C, Durandez R, Serradilla R, Guarner C, Planas R, Arroyo V, Navasa $\mathrm{M}$ : Norfloxacin vs. ceftriaxone in the prophylaxis of infections in patients with advanced cirrhosis and haemorrhage. Gastroenterology 2006;131:1049-1056.

77 De Franchis R; Baveno V Faculty: Revising consensus in portal hypertension: report of the Baveno $\mathrm{V}$ consensus workshop on methodology of diagnosis and therapy in portal hypertension. J Hepatol 2010;53:762-768.

78 Aparicio JR, Such J, Pascual S, Arroyo A, Plazas J, Girona E, Gutiérrez A, de Vera F, Palazón JM, Carnicer F, Pérez-Mateo M: Development of quinolone-resistant strains of Escherichia coli in stools of patients with cirrhosis undergoing norfloxacin prophylaxis: clinical consequences. J Hepatol 1999;31:277-283.

79 Artru F, Louvet A, Ruiz I, et al: Liver transplantation in the most severely ill cirrhotic patients: a multicentre study in acute-on-chronic liver failure grade 3. J Hepatol 2017;67:708-715.

80 Fagiouli S, Colli A, Bruno R, et al.; 2011 AISF Single Topic Group: Management of infections pre-and postliver transplantation: report of an AISF consensus conference. J Hepatol 2014;60:1075-1089.

81 Fernandez J, Tandon P, Mensa J, Garcia-Tsao G: Antibiotic prophylaxis in cirrhosis: good and bad. Hepatology 2016;63:2019-2031. 